\title{
Lie algebra classification, conservation laws and invariant solutions for modification of the generalization of the Emden-Fowler equation.
}

Yeisson Acevedo Agudelo ${ }^{1}$, Gabriel Loaiza Ossa ${ }^{1}$, Oscar Londoño Duque ${ }^{1}$, and Danilo García Hernández ${ }^{2}$

${ }^{1}$ Universidad EAFIT

${ }^{2}$ IMECC

April 7, 2021

\begin{abstract}
We obtain the optimal system's generating operators associated to a modification of the generalization of the Emden-Fowler Equation. equation. Using those operators we characterize all invariant solutions associated to a generalized. Moreover, we present the variational symmetries and the corresponding conservation laws, using Noether's theorem and Ibragimov's method. Finally, we classify the Lie algebra associated to the given equation.
\end{abstract}

\section{Hosted file}

Paper Ibragimov.pdf available at https://authorea.com/users/406259/articles/516981-liealgebra-classification-conservation-laws-and-invariant-solutions-for-modification-ofthe-generalization-of-the-emden-fowler-equation 